\title{
USO DA GRADE ARADORA SUPERPESADA, PESADA E ARADO DE DISCOS NA INCORPORAÇÃO DE CALCÁRIO EM PROFUNDIDADE E NA PRODUÇÃO DE MILHO
}

\author{
RENATO DE M. PRADO ${ }^{1}$, WILLIAM NATALE ${ }^{2}$
}

\begin{abstract}
RESUMO: Este trabalho teve o objetivo de avaliar o efeito dos modos de incorporação de calcário na correção da acidez no perfil do solo e na produção do milho. Para tanto, foi conduzido um experimento em Latossolo Vermelho Distrófico, textura argilosa, em Uberlândia - MG, no período de maio de 1995 a março de 1997. O delineamento experimental foi em esquema de parcelas subdivididas. As parcelas principais foram constituídas pelos modos de incorporação do calcário: grade aradora pesada (14 discos de $0,86 \mathrm{~m}$ ) e grade niveladora (60 discos de $0,56 \mathrm{~m})$; arado de disco (4 discos de 0,66 m) e grade niveladora; grade aradora superpesada $(14$ discos de $0,86 \mathrm{~m})$ e grade niveladora; as subparcelas foram as doses de calcário dolomítico: 0; 6 e 9,2 $\mathrm{t} \mathrm{ha}^{-1}$. O modo de incorporação do calcário afetou a eficiência da calagem no perfil do solo. A gradagem pesada não foi adequada para a incorporação do calcário. A aração com arado de disco mais gradagem niveladora teve desempenho satisfatório, atingindo até $0,20 \mathrm{~m}$ de profundidade. A gradagem com grade aradora superpesada proporcionou maior uniformidade e profundidade de incorporação, com neutralização da acidez do solo até $0,30 \mathrm{~m}$ de profundidade. $\mathrm{O}$ milho respondeu linearmente à aplicação do calcário, e o modo alternativo de incorporação pela gradagem com grade superpesada proporcionou maior produção.
\end{abstract}

PALAVRAS-CHAVE: modos de incorporação, calagem, Zea mays L.

\section{USE OF THE SUPER HEAVY AND HEAVY HARROW AND DISK PLOW IN LIMESTONE MATERIAL INCORPORATION IN CORN CROP}

SUMMARY: The objective of the present study was to assess the effect of the modes of lime incorporation on the correction of soil acidity and on corn production. An experiment was conducted on Typic Hapludox of clay texture in Uberlândia - MG, Brazil, from May 1995 to March 1997. The experimental design consisted of a split-plot scheme. The main plots consisted of the modes of lime incorporation: heavy harrow (14 disks of $0.86 \mathrm{~m}$ ) and leveling harrow (60 disks of $0.56 \mathrm{~m})$; disk plow (4 disks of $0.66 \mathrm{~m}$ ) and a leveling harrow; super heavy harrow (14 disks of $0.86 \mathrm{~m}$ ) and a leveling harrow. The subplots were doses of dolomitic lime of $0 ; 6$ and $9.2 \mathrm{tha}^{-1}$. The mode of lime incorporation affected the efficiency of liming in terms of soil profile. The heavy harrow was inadequate for lime incorporation. Plowing with a super heavy harrow plus level harrowing showed a satisfactory performance, reaching a depth of as much as $0.20 \mathrm{~m}$. Harrowing with a super heavy harrow provided a greater uniformity and depth of incorporation, with neutralization of soil acidity to a depth of $0.30 \mathrm{~m}$. Corn responded in a linear manner to lime incorporation, with the mode of incorporation by harrowing with a super heavy harrow providing a greater production.

KEYWORDS: incorporation manners, liming, Zea mays L.

\footnotetext{
${ }^{1}$ Eng ${ }^{\mathrm{o}}$ Agrônomo, Prof. Dr., Departamento de Solos e Adubos, Faculdade de Ciências Agrárias e Veterinárias - UNESP, Via de Acesso Prof. Paulo Donato Castellane, km 5, 14884.900, Jaboticabal - SP, e-mail: rmprado@ fcav.unesp.br

${ }^{2}$ Eng $^{\mathrm{O}}$ Agrônomo, Prof. Adjunto, Departamento de Solos e Adubos, Faculdade de Ciências Agrárias e Veterinárias - UNESP. Bolsista CNPq.

Recebido pelo Conselho Editorial em: 21-6-2002

Aprovado pelo Conselho Editorial em: 14-11-2003
} 


\section{INTRODUÇÃO}

A calagem em solos tropicais torna-se importante, em função da predominância de áreas agrícolas com elevada acidez do solo (MALAVOLTA, 1980; QUAGGIO, 2000). Nessas condições, para o cultivo da cultura do milho, o uso do calcário é fundamental para atingir maior produção de grãos (OLIVEIRA et al., 1997).

A questão da prática da calagem no Brasil enfrenta vários problemas, destacando-se a reduzida quantidade de insumo utilizada, quando comparada a sua necessidade, visto que se empregam cerca de 20 milhões $\mathrm{t}_{\mathrm{ano}}{ }^{-1}$, embora a capacidade de moagem seja de cerca de 50 milhões $\mathrm{t} \mathrm{ano}^{-1}$ (QUAGGIO, 2000). Com a subutilização, a relação média calcário/adubo é baixa (cerca de 1:1), comparada ao que é recomendado pela FAO (cerca de 4:1) para solos tropicais (LOPES, 1994). Além do aspecto quantidade, existe outro problema que é a aplicação inadequada do corretivo, ou seja, o uso de dose de calcário calculada para incorporação a $0,20 \mathrm{~m}$ de profundidade, porém incorporada superficialmente, geralmente na camada de 0 a $0,10 \mathrm{~m}$, utilizando grades aradoras intermediárias ou, até, grades niveladoras. Isso traz reflexos negativos, tanto nos atributos físicos do solo, causando degradação e erosão (FREITAS, 1992), como nos químicos, podendo reduzir a disponibilidade de micronutrientes (KÜPPER et al., 1968; MALAVOLTA, 1980).

O problema da supercalagem foi evidenciado por DENARDIN (1984), que estudou os efeitos da ação da grade aradora pesada na incorporação de calcário (dose calculada para a camada de 0 a $0,25 \mathrm{~m}$ ) e as alterações em alguns atributos químicos no perfil de um Latossolo Vermelho distrófico. O autor observou que os teores de $\mathrm{Ca}+\mathrm{Mg}$ na camada superficial $(0$ a $0,15 \mathrm{~m})$ se apresentaram em mais que o dobro do recomendado, ao passo que, na camada abaixo de $0,15 \mathrm{~m}$, as concentrações de $\mathrm{Al}$ permaneceram altas, restringindo o crescimento de raízes e expondo as culturas à erosão e veranicos.

É fato conhecido que o calcário, em geral, apresenta baixa solubilidade e, devido a isso, necessita de adequado contato com as partículas de solo para reagir. Assim, a incorporação ao solo é fundamental para a correção da acidez; entretanto, normalmente, os agricultores negligenciam sua importância, o que resulta em menor eficiência da calagem (QUAGGIO, 2000). Segundo ANDRADE (1991) a eficácia no uso de calcário envolve diversos fatores, como: a quantidade, a qualidade, a profundidade de incorporação e o intervalo entre as aplicações. Desses aspectos, o autor destaca a importância da profundidade de incorporação na eficiência da calagem.

As informações sobre a eficiência de equipamentos na incorporação de corretivos a profundidades maiores que $0,20 \mathrm{~m}$, e com homogeneidade adequada, são insuficientes. No Brasil, a incorporação de calcário é feita, em geral, com grades intermediárias ou até niveladoras. Assim, os arados estão perdendo espaço para as grades, devido ao custo operacional (DALLMEYER, 1986). Entretanto, na literatura, os trabalhos indicam que o método convencional com arado é superior ao da gradagem pesada (OLIVEIRA et al., 1996; WEIRICH NETO et al., 2000), embora se admita que a mistura do corretivo com a massa de solo, na camada superficial, seja melhor com a grade aradora, comparado ao arado (MAIA et al., 1996).

Com relação à profundidade de incorporação, observa-se que as culturas anuais apresentam respostas diferentes quanto à produção. A incorporação com arado de aivecas e gradagem niveladora em maiores profundidades (até $0,30 \mathrm{~m}$ ) pode neutralizar a acidez do solo em subsuperfície, permitindo maior desenvolvimento radicular, com reflexo positivo na produção de milho (GONZALES-ÉRICO et al., 1979; ALONÇO et al., 1992), especialmente quando ocorrerem veranicos (DEDECEK et al., 1986). Porém, ausência de resposta na produção de milho também é verificada, entretanto, em sistema de produção sob plantio direto (PÖTTKER \& BEN, 1998; MOREIRA et al., 2001).

O trabalho teve o objetivo de avaliar o efeito dos modos de incorporação de calcário com gradagem pesada e aração e gradagem, comparando com gradagem superpesada, na produção do milho e na correção da acidez no perfil do solo. 


\section{MATERIAL E MÉTODOS}

O experimento foi conduzido na Fazenda Beija-Flor, em Uberlândia - MG. O clima local, segundo a classificação de Köeppen, é mesotérmico com verão quente e úmido ( $\mathrm{Cwa}$ ). O experimento foi conduzido de maio-1995 a março-1997, sendo o solo um Latossolo Vermelho distrófico. O conteúdo de argila nas camadas de 0 a $0,20 \mathrm{~m}$ e de 0,20 a $0,30 \mathrm{~m}$ é 410 e $425 \mathrm{~g} \mathrm{~kg}^{-1}$, respectivamente. A área do teste permaneceu sob plantio de eucalipto por mais de 10 anos; em seguida, realizou-se cultivo com preparo convencional por meio de aração e gradagem, e semeadura de arroz de sequeiro (1994-1995). No ano agrícola seguinte (1995-1996), incorporou-se o calcário (maio-1995) com os tratamentos, cultivando-se aveia-preta para a formação de cobertura morta para a implantação do sistema plantio direto, conforme descrito no trabalho de PRADO \& ROQUE (2002). No ano agrícola 1996-1997, introduziu-se este experimento com a cultura do milho, semeado em outubro-1996 (17 meses após a incorporação do calcário), de forma a possibilitar a expressão da máxima reação do corretivo, visto que, na literatura, existem indicações de que esse período ocorre em 18 meses (NATALE \& COUTINHO, 1994).

Antes da aplicação do calcário e do cultivo da aveia-preta (abril-1995), foram coletadas 20 subamostras de solo, por camada, aleatoriamente, em toda área do teste, para compor a amostra composta das camadas de 0 a 0,$10 ; 0,10$ a 0,20 e 0,20 a $0,30 \mathrm{~m}$. Os resultados das análises químicas para fins de fertilidade do solo encontram-se na Tabela 1.

TABELA 1. Propriedades químicas do Latossolo Vermelho distrófico, antes da aplicação do calcário

\begin{tabular}{ccccccccccc}
\hline Camada & $\begin{array}{c}\mathrm{pH} \\
\mathrm{CaCl}_{2}\end{array}$ & M.O. & $\begin{array}{c}\mathrm{P} \\
\text { (resina) }\end{array}$ & $\mathrm{K}$ & $\mathrm{Ca}$ & $\mathrm{Mg}$ & $(\mathrm{H}+\mathrm{Al})$ & $\mathrm{SB}$ & $\mathrm{T}$ & $\mathrm{V}$ \\
\hline $\mathrm{m}$ & & $\mathrm{g} \mathrm{dm}^{-3}$ & $\mathrm{mg} \mathrm{dm}^{-3}$ & & & & $\mathrm{mmol}_{\mathrm{c}} \mathrm{dm}^{-3}$ & & & $\%$ \\
\hline 0 a 0,10 & 4,3 & 17 & 5 & 0,6 & 9 & 1 & 59 & 10,6 & 69,6 & 15 \\
0,10 a 0,20 & 4,1 & 16 & 3 & 0,4 & 8 & 1 & 57 & 9,4 & 66,4 & 14 \\
0,20 a 0,30 & 4,0 & 15 & 3 & 0,3 & 5 & 1 & 58 & 6,3 & 64,3 & 10 \\
\hline
\end{tabular}

Foi adotado o delineamento experimental em esquema de parcelas subdivididas, com as parcelas principais organizadas em blocos com três repetições. Os tratamentos principais, parcelas, foram constituídos pelos seguintes modos de incorporação do calcário: 1) metade da dose distribuída a lanço, seguido da operação com grade aradora pesada $(\mathrm{GP}+\mathrm{GN})$ com controle remoto (14 discos de $0,86 \mathrm{~m}$ ) (34 polegadas), espaçados de $0,34 \mathrm{~m}$, com massa total de $2932 \mathrm{~kg}$ e largura de corte $2,21 \mathrm{~m}$, tracionada por trator de pneu $4 \times 4$ (Valmet 148x4) com 107,4 kW (146 cv) e metade da dose, também a lanço, incorporado com grade niveladora (60 discos de $0,56 \mathrm{~m})$ (22 polegadas); 2) metade da dose distribuída a lanço, incorporada com arado de discos lisos $(\mathrm{A}+\mathrm{GN})(4$ discos $0,66 \mathrm{~m})$ (26 polegadas) e metade da dose também distribuída a lanço, incorporada com grade niveladora (60 discos de 0,56 m) (22 polegadas); 3) dose inteira do calcário aplicado a lanço e, em seguida, incorporado com grade aradora superpesada $(\mathrm{GSP}+\mathrm{GN})$, com controle remoto (14 discos de $0,86 \mathrm{~m})$ (34 polegadas), espaçados de $0,44 \mathrm{~m}$, com massa total de $3.814 \mathrm{~kg}$ e largura de corte $2,65 \mathrm{~m}$, tracionada por trator de esteira com $103 \mathrm{~kW}(140 \mathrm{cv})$ e com grade niveladora (60 discos de $0,56 \mathrm{~m})$ (22 polegadas). Nota-se que, embora as grades apresentem mesmo número e diâmetro de discos, variaram na massa do equipamento e distância entre discos, fatores que tecnicamente diferenciam as grades em pesada e superpesada e, conseqüentemente, sua ação em profundidade. Nas subparcelas, os tratamentos secundários constituíram-se de doses de calcário dolomítico (PRNT $=64 \% ; \mathrm{RE}=87,3 \% ; \mathrm{PN}=73,3 \%$; $\mathrm{CaO}=37,2 \%$ e $\mathrm{MgO}=27,0 \%$ ), como segue: $\mathrm{D}_{0}=$ zero; $\mathrm{D}_{1}=$ dose para elevar $\mathrm{V}$ a $70 \% ; \mathrm{D}_{2}=$ dose para elevar $\mathrm{V}$ a $100 \%$, as quais corresponderam a $0 ; 6$ e 9,2 t de calcário por ha, respectivamente.

As parcelas experimentais foram compostas por oito linhas de milho (híbrido triplo, Pionner 3071), espaçadas de 0,9 m nas entrelinhas, com densidade populacional inicial de 6 plantas por metro; 
considerou-se, porém, as quatro linhas centrais como úteis para as avaliações. A semeadura direta de milho sobre resteva de aveia-preta foi realizada em 9-10-1996. A área ficou em pousio durante nove meses, ou seja, do período do manejo da aveia-preta (1-1996) até a semeadura do milho (10-1996).

A adubação básica de semeadura constou da aplicação de $400 \mathrm{~kg} \mathrm{ha}^{-1}$ da fórmula 8-18-16 + $0,25 \%$ de $\mathrm{Zn}$ e, em cobertura aos 30 dias após a emergência, $550 \mathrm{~kg} \mathrm{ha}^{-1}$ de sulfato de amônio $\left(110 \mathrm{~kg} \mathrm{~N} \mathrm{ha}^{-1}\right)$ e $83 \mathrm{~kg} \mathrm{ha}^{-1}$ de cloreto de potássio $\left(50 \mathrm{~kg} \mathrm{~K}_{2} \mathrm{O} \mathrm{ha}^{-1}\right)$.

Aos 150 dias após a semeadura, realizaram-se a colheita e as amostragens de solo nas camadas de 0 a 0,$10 ; 0,10$ a 0,20 e 0,20 a $0,30 \mathrm{~m}$, a fim de avaliar os efeitos da calagem no perfil do solo, após 22 meses da incorporação. Foram coletadas 20 subamostras por parcela, nas entrelinhas da cultura, a fim de constituir uma amostra composta. A análise de solo seguiu a metodologia de RAIJ et al. (1987).

Os dados foram submetidos à análise de variância. As médias dos resultados foram comparados pelo teste de Tukey $(\mathrm{P}<0,05)$, realizando-se o estudo de regressão e escolhendo-se as equações significativas pelo teste $\mathrm{F}(\mathrm{P}<0,05)$, com maior coeficiente de determinação.

\section{RESULTADOS E DISCUSSÃO}

Analisando-se os resultados, pode-se verificar que houve efeito significativo dos modos de incorporação do calcário na produção de grãos de milho (Figura 1a). Observa-se que o modo de incorporação de calcário, com grade superpesada e grade niveladora (GSP $+\mathrm{GN})$, foi mais eficiente que o modo convencional (aração seguida de gradagem niveladora - $\mathrm{A}+\mathrm{GN}$ ), que, por sua vez, foi superior à incorporação por grade pesada (GP+GN).
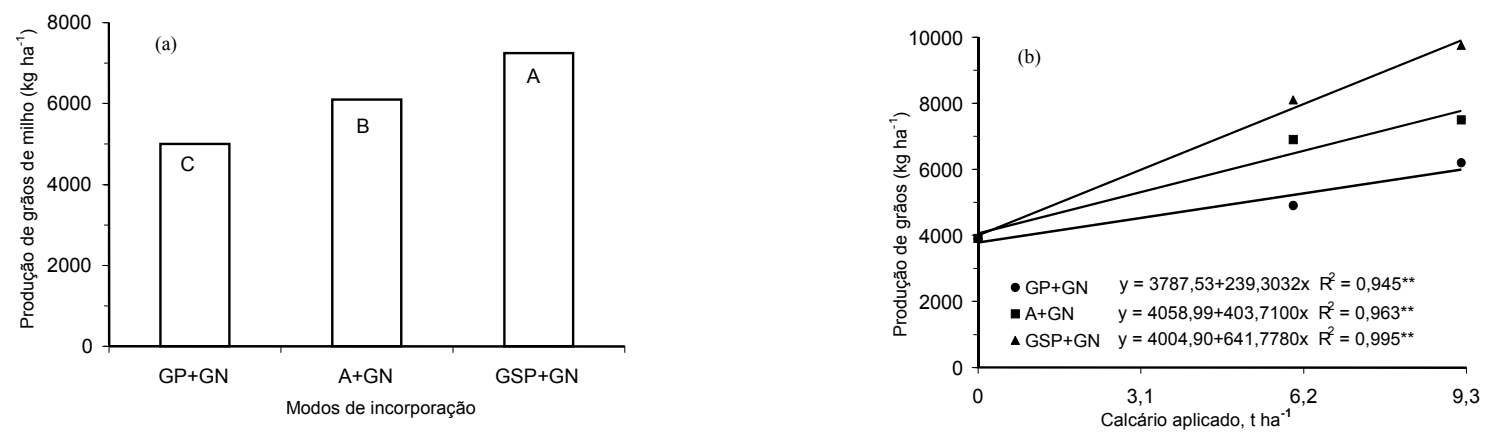

Colunas com letras iguais não se diferenciam pelo teste de Tukey $(\mathrm{P}<0,05)$ (D.M.S. $=524,4)$.

** Resultado significativo pelo teste $\mathrm{F}(\mathrm{P}<0,01)$.

FIGURA 1. Efeito dos modos de aplicação (a) e de doses de calcário (b) a partir da incorporação com grade pesada e grade niveladora $(\mathrm{GP}+\mathrm{GN})$, aração e grade niveladora $(\mathrm{A}+\mathrm{GN})$ e grade superpesada e grade niveladora $(\mathrm{GSP}+\mathrm{GN})$, em um Latossolo Vermelho distrófico, na produção de grãos de milho.

Acrescenta-se que o método convencional foi superior ao da gradagem pesada, o que não está de acordo com OLIVEIRA et al. (1996) e WEIRICH NETO et al. (2000), que observaram terem sido essas duas formas de incorporação semelhantes na produção de milho. Entretanto, concorda com outros autores (GONZALES-ÉRICO et al., 1979; ALONÇO et al., 1992) que relataram ser a prática de incorporação convencional de aração, seguida de gradagem, superior à da gradagem pesada. Essa divergência de resultados quanto aos modos de incorporação, em relação à produção das culturas, pode depender, fundamentalmente, do grau de acidez subsuperficial, da tolerância da planta à acidez do solo, além da quantidade e características do corretivo usado, com diferentes granulometrias e tempos de reação. Como modo opcional de incorporação do calcário, a grade superpesada mostrou-se promissora na produção de milho, podendo substituir o modo convencional por apenas uma operação. 
A correção da acidez no perfil do solo foi alterada significativamente e de forma distinta, dependendo da forma de incorporação do calcário (Tabela 2). Os modos de incorporação com aração e gradagem e com gradagem superpesada foram semelhantes na camada superficial do solo $(0$ a $0,10 \mathrm{~m})$, exceto para o $\mathrm{Mg}$ e $\mathrm{V} \%$; a gradagem pesada foi o modo de incorporação que mais elevou os valores de $\mathrm{pH}, \mathrm{Ca}, \mathrm{SB}$ e V\% do solo. Na camada de 0,10 a $0,20 \mathrm{~m}$, os modos de incorporação com aração e gradagem e com gradagem superpesada foram superiores à gradagem pesada, em relação a todos os atributos químicos avaliados, enquanto na camada mais profunda $(0,20$ a $0,30 \mathrm{~m})$ se destacou a incorporação com gradagem superpesada na neutralização da acidez do solo.

TABELA 2. Efeito dos modos de incorporação de calcário com grade pesada e grade niveladora $(\mathrm{GP}+\mathrm{GN})$, aração e grade niveladora $(\mathrm{A}+\mathrm{GN})$ e grade superpesada e grade niveladora $(\mathrm{GSP}+\mathrm{GN})$ sobre os atributos químicos do Latossolo Vermelho distrófico (camadas de 0 até $0,30 \mathrm{~m}$ ), após 22 meses da incorporação do corretivo.

\begin{tabular}{|c|c|c|c|c|}
\hline \multirow{2}{*}{ Atributos Químicos } & \multicolumn{4}{|c|}{ Modos de Incorporação } \\
\hline & $\mathrm{GP}+\mathrm{GN}$ & $\mathrm{A}+\mathrm{GN}$ & $\mathrm{GSP}+\mathrm{GN}$ & DMS (5\%) \\
\hline & \multicolumn{4}{|c|}{ camada de 0 a $0,10 \mathrm{~m}$} \\
\hline $\mathrm{pH}$ & $5,2 \mathrm{~A}^{(1)}$ & $5,0 \mathrm{~B}$ & 5,0 B & 0,11 \\
\hline $\mathrm{Ca}$ & $28 \mathrm{~A}$ & $24 \mathrm{~B}$ & $25 \mathrm{AB}$ & 5,32 \\
\hline $\mathrm{Mg}$ & $6,4 \mathrm{~A}$ & $5,9 \mathrm{~A}$ & 4,7 B & 0,76 \\
\hline $\mathrm{H}+\mathrm{Al}$ & $28 \mathrm{~B}$ & $30 \mathrm{~A} \mathrm{~B}$ & $32 \mathrm{~A}$ & 3,02 \\
\hline SB & $36,4 \mathrm{~A}$ & $31,6 \mathrm{~B}$ & $32,0 \mathrm{~B}$ & 3,81 \\
\hline \multirow[t]{2}{*}{$\mathrm{V} \%$} & $53 \mathrm{~A}$ & $48 \mathrm{~B}$ & $45 \mathrm{C}$ & 1,66 \\
\hline & & \multicolumn{3}{|c|}{ camada de 0,10 a $0,20 \mathrm{~m}$} \\
\hline $\begin{array}{l}\mathrm{PH} \\
\mathrm{Ca}\end{array}$ & $\begin{array}{l}4,1 \mathrm{C} \\
6 \mathrm{~B}\end{array}$ & $\begin{array}{l}5,0 \mathrm{~B} \\
24 \mathrm{~A}\end{array}$ & $27 \mathrm{~A}$ & 2,93 \\
\hline $\mathrm{Mg}$ & $2 \mathrm{~B}$ & $6 \mathrm{~A}$ & $6 \mathrm{~A}$ & 0,94 \\
\hline $\mathrm{H}+\mathrm{Al}$ & $52 \mathrm{~A}$ & $34 \mathrm{~B}$ & $32 \mathrm{~B}$ & 4,93 \\
\hline SB & $9 \mathrm{~B}$ & $32 \mathrm{~A}$ & $36 \mathrm{~A}$ & 5,64 \\
\hline \multirow[t]{2}{*}{$\mathrm{V} \%$} & $14 \mathrm{~B}$ & $47 \mathrm{~A}$ & $49 \mathrm{~A}$ & 5,80 \\
\hline & & \multicolumn{2}{|c|}{ camada de 0,20 a $0,30 \mathrm{~m}$} & \\
\hline $\mathrm{pH}$ & $4,0 \mathrm{C}$ & $4,1 \mathrm{~B}$ & $4,9 \mathrm{~A}$ & 0,07 \\
\hline $\mathrm{Ca}$ & $5 \mathrm{C}$ & $10 \mathrm{~B}$ & $18 \mathrm{~A}$ & 1,48 \\
\hline $\mathrm{Mg}$ & $1 \mathrm{C}$ & $2 \mathrm{~B}$ & $5 \mathrm{~A}$ & 0,65 \\
\hline $\mathrm{H}+\mathrm{Al}$ & $51 \mathrm{~A}$ & $48 \mathrm{~A}$ & $33 \mathrm{~B}$ & 3,58 \\
\hline SB & 7,0 C & $13,8 \mathrm{~B}$ & $24,2 \mathrm{~A}$ & 1,93 \\
\hline V\% & $12 \mathrm{C}$ & $20 \mathrm{~B}$ & $41 \mathrm{~A}$ & 2,47 \\
\hline
\end{tabular}

Estes resultados sugerem que os efeitos benéficos da calagem, após 22 meses da aplicação, foram detectados até a camada de $0,10 \mathrm{~m}$ quando o modo de incorporação do calcário foi a gradagem pesada; até $0,20 \mathrm{~m}$, quando o calcário foi incorporado com aração e gradagem ou gradagem superpesada, e até $0,30 \mathrm{~m}$, somente com a incorporação com gradagem superpesada. Observações semelhantes foram feitas por PRADO \& ROQUE (2002), após nove meses da aplicação do calcário.

Incrementos significativos nos teores de $\mathrm{Ca}$, valores de $\mathrm{pH}, \mathrm{SB}$ e $\mathrm{V} \%$ na camada de 0 a $0,10 \mathrm{~m}$, advindos da incorporação rasa do calcário com gradagem pesada, foram observados por DEDECEK et al. (1986), DENARDIN (1984) e DALLMEYER (1986). Isso pode reduzir de forma significativa a disponibilidade de micronutrientes no solo, fato amplamente discutido na literatura (KÜPPER et al., 
1968; MALAVOLTA, 1980). As demais propriedades químicas do solo, como K, P, M.O. e CTC, não foram afetadas pelos tratamentos, razão pela qual os dados não são apresentados.

A incorporação convencional do calcário, média das três doses, com arado e grade superpesada, acarretou em neutralização da acidez a maiores profundidades, comparada com a grade pesada (Tabela 2). Resultados similares foram obtidos por MAIA et al. (1996), que observaram melhor distribuição do calcário no perfil do solo incorporado pelo arado de discos, quando comparado à grade pesada, embora se possa admitir que a mistura do corretivo com a camada de solo no plano horizontal, na camada superficial de atuação da grade pesada, seja melhor, quando comparada ao arado de discos.

Acrescenta-se, ainda, que a superioridade da grade superpesada em relação aos demais tratamentos deve-se à maior profundidade de atuação, e que o movimento de rotação dos discos nas grades é superior ao do arado. Isso reflete em mistura eficientemente do calcário com maior massa de solo e, conseqüentemente, em aumento na velocidade de reação do corretivo.

Observou-se, ainda, que, para cada tonelada de calcário aplicado, resultou incremento na produção de grãos de milho de 239; 404 e $642 \mathrm{~kg} \mathrm{ha}^{-1}$, para incorporação com grade pesada, arado de disco e grade superpesada, respectivamente (Figura 1b). Esse efeito da calagem na produção do milho foi linear, estando a produção máxima associada à maior dose de corretivo empregada, $9,3 \mathrm{t} \mathrm{ha}^{-1}$ de calcário, ou seja, a dose calculada para elevar o $\mathrm{V}$ a 100\%. Esses resultados assemelham-se aos obtidos por OLIVEIRA et al. (1997), que observaram produção máxima do milho com índice de $90 \%$ de saturação por bases, estimado pelo método indireto da recomendação de calcário.

Esse resultado mostra, portanto, a resposta positiva da cultura do milho à correção da acidez do solo em sistema plantio direto, confirmando a informação de SÁ (1993) e PRADO (2001), a partir de experimentos conduzidos na região Sul do País (Carambeí - PR) e do Cerrado (Uberlândia - MG), respectivamente, ambos em Latossolo Vermelho distrófico. Outros autores não observaram resposta do milho à calagem em sistema plantio direto, quando utilizaram o híbrido AG 9012, cultivado em Latossolo Vermelho-Escuro e em Latossolo Roxo ( $\mathrm{pH}$ em água $=4,6-4,7, \mathrm{Ca}=19-25$ e $\mathrm{Mg}=7$ $10 \mathrm{mmol}_{\mathrm{c}} \mathrm{dm}^{-3}$ ) (PÖTTKER \& BEN, 1998) ou para o híbrido XL 8392 cultivado em Latossolo Vermelho-Escuro ( $\mathrm{pH}$ em $\mathrm{CaCl}_{2}=4,8-5,1 ; \mathrm{Ca}=28-47$ e $\mathrm{Mg}=18-26 \mathrm{mmol}_{\mathrm{c}} \mathrm{dm}^{-3}$ ) (MOREIRA et al., 2001). As diferenças encontradas na literatura podem ser atribuídas às condições edafoclimáticas das áreas experimentais e, principalmente, ao uso de híbridos distintos. Essa ausência de resposta das culturas à calagem, observada em plantio direto, pode ser explicada, ainda, pelo fato de os teores de $\mathrm{Ca}, \mathrm{Mg}$ e $\mathrm{K}$ estarem em níveis adequados no solo, apresentando relação adequada com o $\mathrm{Al}^{+3}$ (CAIRES et al., 1998).

A análise de regressão avaliou os efeitos dos diversos modos de incorporação sobre a acidez do solo nas camadas de 0 a $0,30 \mathrm{~m}$ (Figura 2). A gradagem pesada afetou apenas a camada superficial do solo $(0-0,10 \mathrm{~m})$, aumentando o valor de $\mathrm{pH}$, a soma de bases, a saturação por bases e reduzindo a acidez potencial. Na gradagem superpesada, esse efeito nos atributos químicos do solo ocorreu nas três camadas analisadas (Figura 2). No modo convencional de aração, houve efeito pronunciado em todos os atributos químicos analisados até a camada de $0,20 \mathrm{~m}$, sendo na camada de 0,20 a $0,30 \mathrm{~m}$, observadas duas situações: uma em que não houve efeito nos atributos químicos do solo $\mathrm{H}+\mathrm{Al}$ e outra, em que, apesar de haver significância, o efeito foi de baixa expressão, a exemplo do incremento no valor de $\mathrm{pH}$, soma de bases e saturação por bases (Figura 2), considerando-se o baixo coeficiente angular da reta do gráfico correspondente à camada subsuperficial, comparado às camadas superficiais (até $0,20 \mathrm{~m}$ ). 

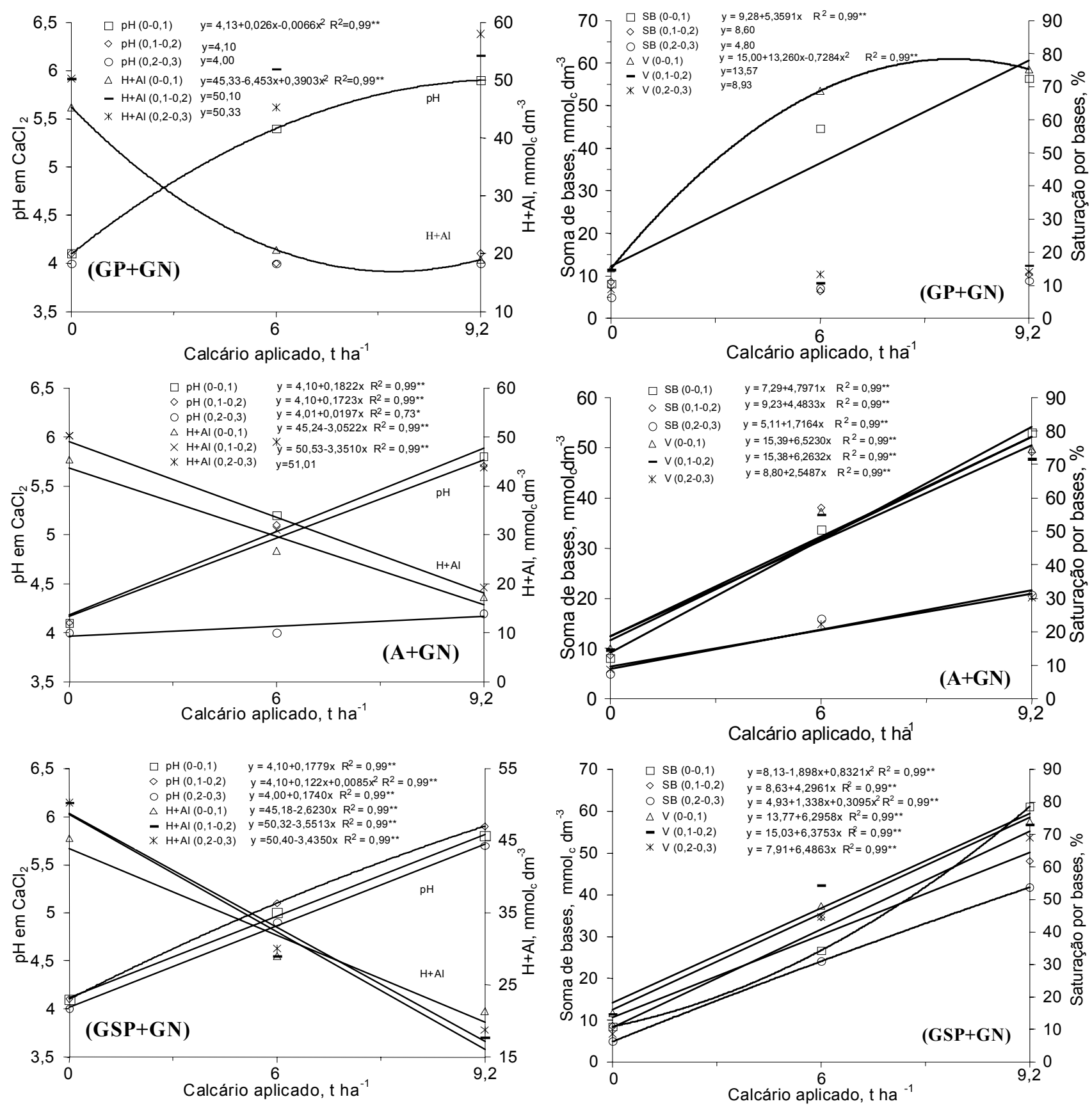

FIGURA 2. Efeitos de doses e modos de incorporação do calcário com gradagem pesada e gradagem niveladora $(\mathrm{GP}+\mathrm{GN})$, aração e gradagem niveladora $(\mathrm{A}+\mathrm{GN})$ e gradagem superpesada e gradagem niveladora $(\mathrm{GSP}+\mathrm{GN})$, nos atributos químicos do Latossolo Vermelho distrófico, em diferentes profundidades, após 22 meses da incorporação do corretivo.

É importante destacar que, independentemente do modo de incorporação do calcário, a saturação por bases calculada não foi atingida (Figura 2), ainda que o método utilizado para estimar a necessidade de calcário, pela elevação da saturação por bases, seja validado. Esse fato é relatado na literatura, sendo atribuída à baixa taxa de reatividade do calcário, que a legislação vigente superestima, considerando o período de três meses (NATALE \& COUTINHO, 1994). Entretanto, segundo esses autores, em condições de campo, essa reatividade preconizada ocorre apenas 18 meses após a 
incorporação do calcário ao solo. Outros autores citam que a máxima reação do calcário no solo, em condições de campo, ocorre somente no período de 18 a 33 meses após a sua incorporação ao solo (OLIVEIRA et al., 1997; QUAGGIO et al., 1982). Além disso, na aplicação de doses maiores de calcário, ocorre deslocamento da reação de equilíbrio da solubilização do corretivo e a formação de novos minerais no solo em formas de hidróxido pouco solúvel (TESCARO, 1998). Outro fator é o grau de mistura com as partículas do solo, pois as operações de incorporação no campo são heterogêneas, resultando em pequenas zonas ao redor das partículas excessivamente corrigidas, separadas por espaços sem correção (QUAGGIO, 2000).

As duas primeiras hipóteses estão enfraquecidas, visto que houve tempo suficiente para a reação máxima do calcário no solo, ou seja, transcorreram 22 meses entre a incorporação do corretivo e a amostragem do solo. Dentre as possíveis hipóteses que explicam a dificuldade de atingir a saturação por bases pretendida, a que exprime a dificuldade de mistura do material corretivo ao solo pode ser a mais aceitável. Neste trabalho, houve efeitos diferenciados dos modos de incorporação na correção da acidez, sendo a grade superpesada a que mais se aproximou da saturação por bases calculada, nas três camadas de solo analisadas (Figura 2). Isto pode caracterizar maior homogeneidade de incorporação entre as partículas de calcário e a massa de solo.

\section{CONCLUSÕES}

Os modos de incorporação do calcário afetaram a acidez ao longo do perfil do solo.

A gradagem pesada mais a gradagem niveladora não foram adequadas para a incorporação do calcário em profundidade; a incorporação com arado de disco, seguida da grade niveladora, teve desempenho satisfatório, atingindo até $0,20 \mathrm{~m}$ de profundidade; o uso da grade superpesada propiciou maior uniformidade e profundidade de incorporação, neutralizando a acidez do solo até $0,30 \mathrm{~m}$.

A produção de milho respondeu linearmente à aplicação do calcário; o modo de incorporação por meio de gradagem superpesada proporcionou a maior produção.

\section{REFERÊNCIAS BIBLIOGRÁFICAS}

ALONÇO, A.S.; FERREIRA, O.O. Incorporação profunda de fertilizantes e calcário: sua influência na produção de milho (Zea mays L.) sob estresse hídrico e sobre algumas propriedades físicas e químicas de um solo de cerrado. In: CONGRESSO BRASILEIRO DE ENGENHARIA AGRÍCOLA, 20., 1991, Londrina. Anais... Londrina: Sociedade Brasileira de Engenharia Agrícola, 1992. p.57.

ANDRADE, L.A.B. Calagem para a cultura da cana-de-açúcar. Informe Agropecuário, Belo Horizonte, v.15,p.15-16, 1991.

CAIRES, E.F.; MADRUGA, E.F.; CHUEIRI, W.A.; FIGUEIREDO, A. Alterações das características químicas do solo e resposta da soja ao calcário e gesso aplicados na superfície em sistema de cultivo sem preparo do solo. Revista Brasileira de Ciência do Solo, Campinas, v.22, p.27-34, 1998.

DALLMEYER, A.V. As máquinas utilizadas na distribuição e incorporação de calcário. In: SIMPÓSIO SOBRE APLICAÇÃO DE CALCÁRIO NA AGRICULTURA, 1., 1986, Campinas. Anais... Campinas: Fundação Cargill, 1986. p.23-9.

DEDECEK, R.A.; PEREIRA, J.; IKE, M.; IWATA, F. Efeito de profundidade de aração inicial, modos de adubação corretiva e sistemas de preparo do solo na produção de soja em solo de cerrados. Revista Brasileira de Ciência do Solo, Campinas, v.10, p.173-80, 1986.

DENARDIN, J.E. Manejo adequado do solo para áreas motomecanizadas. In: SIMPÓSIO DE MANEJO DO SOLO E PLANTIO DIRETO NO SUL DO BRASIL, 1., 1983, Passo Fundo. Anais... Passo Fundo: Empresa Brasileira de Pesquisa Agropecuária, 1984. p.107-23. 
FREITAS, P.L. Manejo físico do solo. In: SIMPÓSIO SOBRE MANEJO E CONSERVAÇÃO DO SOLO NO CERRADO,1., 1992, Goiânia. Anais... Goiânia: Fundação Cargill, 1992. p.117-39.

GONZALES-ÉRICO, E.; KAMPRATH, E.J.; NARDERMAN JR., G.C.; SOARES, W.V. Effect of depth of lime incorporation on the growth of corn on an Oxisol of Central Brasil. Soil Science Society of America Journal, Madison, v.43, p.1155-8, 1979.

KÜPPER, A.; SACCHETTO, M.T.D.; RAIJ, B. van. Formas e níveis de manganês em alguns solos com e sem calagem. Bragantia, Campinas, v.27,p.15-17,1968.

LOPES, A.S. Uso de tecnologia moderna na preservação do meio ambiente. In: SIMPÓSIO NACIONAL DO SETOR DE FERTILIZANTES, 1., 1997, São Paulo. Anais... São Paulo: ANDA, IBRAFOS, 1994. p.247-80.

MAIA, J.C.S.; WEBER, O.L.S.; SGUAREZZI, J.J.; AGUILLERA, L.A.; BOTTAN, A .J.; PEREIRA, L.C.; BEZERRA, E.L. Influência de diferentes sistemas de incorporação de calcário sobre as propriedades químicas de um Latossolo Vermelho-Amarelo, em região de Cerrados Mato-Grossenses. Revista Agricultura Tropical, Cuiabá, v.1, p.41-9,1996.

MALAVOLTA, E. Elementos de nutrição mineral de plantas. São Paulo: Agronômica Ceres, 1980. $251 \mathrm{p}$.

MOREIRA, S.G.; KIEHL, J.C.; PROCHNOW, L.I.; PAULETTI, V. Calagem em sistema de semeadura direta e efeitos sobre a acidez do solo, disponibilidade de nutrientes e produtividade de milho e soja. Revista Brasileira de Ciência do Solo, Campinas, v.25, p.71-81, 2001.

NATALE, W.; COUTINHO, E.L.M. Avaliação da eficiência agronômica de diferentes frações granulométricas de um calcário dolomítico. Revista Brasileira de Ciência do Solo, Campinas, v.18, p.5562, 1994.

OLIVEIRA, E.L.; PARRA, M.S.; COSTA, A. Resposta da cultura do milho, em um Latossolo Vermelho-Escuro álico, à calagem. Revista Brasileira de Ciência do Solo, Campinas, v.21, p.65-70, 1997.

OLIVEIRA, I.P.; KLUTHCOUSKI, J.; YOKOYAMA, L.P.; DUTRA, L.G.; PORTES, T.A.; SILVA, A.E.; PINHEIRO, B.S.; FERREIRA, E.; CASTRO, E.M. Sistema Barreirão: Recuperação/ Renovação de pastagens degradadas em consórcio com culturas anuais. Goiânia: Empresa Brasileira de Pesquisa Agropecuária, 1996. 90 p. (EMBRAPA-CNPAF. Documentos, 64).

PÖTTKER, D.; BEN, J.R. Calagem para uma rotação de culturas no sistema de plantio direto. Revista Brasileira de Ciência do Solo, Campinas, v.22, p.675-84, 1998.

PRADO, R.M,; ROQUE, C.G. Uso alternativo da grade aradora superpesada na correção da acidez do solo em profundidade e na produção da aveia-preta. Revista Brasileira de Ciência do Solo, Campinas, v.26, p.275-81, 2002.

PRADO, R.M. Saturação por bases e híbridos de milho sob sistema plantio direto. Scientia Agricola, Piracicaba, v.58, p.391-4, 2001.

QUAGGIO, J.A. A acidez e calagem em solos tropicais. Campinas: Instituto Agronômico de Campinas, 2000. $111 \mathrm{p}$.

QUAGGIO, J.A.; MASCARENHAS, H.A.A.; BATAGLIA, O.C. Resposta da soja à aplicação de doses crescentes de calcário em Latossolo Roxo distrófico do cerrado. II. Efeito residual. Revista Brasileira de Ciência do Solo, Campinas, v.6, p.113-18, 1982.

RAIJ, B.van; QUAGGIO, J.A.; CANTARELLA, H. Análise química do solo para fins de fertilidade. Campinas: Fundação Cargill, 1987. 107 p. 
SÁ, J.C.M. Manejo da fertilidade do solo no sistema de plantio direto. In: Plantio direto no Brasil. Passo Fundo: Ed. Aldeia Norte, 1993. p.37-59.

TESCARO, M.D. Eficiência do método da saturação de bases para a correção da acidez de um solo álico. In: REUNIÃO BRASILEIRA DE FERTILIDADE DO SOLO E NUTRIÇÃO DE PLANTAS, 23., 1998, Caxambu. Resumos... Lavras: Universidade Federal de Lavras, 1998. p.103.

WEIRICH NETO, P.H.; CAIRES, E.F.; JUSTINO, A.; DIAS, J. Correção da acidez do solo em função de modos de incorporação de calcário. Ciência Rural, Santa Maria, v.30, p.257-61, 2000. 